HISTOLOGICAL FEATURES OF THE NEPHROTIC SYNDROME ASSOCIATED WITH QUARTAN MALARIA

Sir,

Since this article was submitted, an excellent account of nephropathies in West Africa has been published. The histological features of the nephrotic syndrome in children in Ibadan associated with $P$. malariae infection are similar to those described in our article.

Editors: Edington, G. M., and Mainwaring, A. R., 'Nephropathies in West Africa'. The Kidney. International Academy of Pathology Monograph No. 6, Baltimore, U.S.A. The Williams and Wilkins Company, 1966, 488-501.

J. W. KIBUKAMUSOKA

M. S. R. HUTT

Kampala, Uganda

\section{RECOGNITION OF TRAINING LABORATORIES}

The College of Pathologists is at present preparing lists of laboratories recognized as suitable for the training of pathologists. This is preparatory to the introduction of regulations requiring entrants to the College Examinations to have held appointments in such recognized laboratories. Applications to be considered for recognition should be submitted on forms obtainable from the Registrar at the College of Pathologists, 16 Park Crescent, W.1.

\section{T. CRAWFORD} Registrar

\section{POPULATION SCREENING FOR CERVICAL CANCER}

At the Council Meeting of the Association of Clinical Pathologists on 25 January there was a wide-ranging discussion covering the field of exfoliative cytology, especially in relation to population screening for cervical cancer, and the following resolutions were approved:-

1 To support the formation of a joint committee with the College of Pathologists and the British Society for Clinical Cytology, to be concerned with cytology in general, the training of workers in the field, and the problems of nomenclature.

2 The Technical Methods Committee of the Association of Clinical Pathologists is considering the publication of a series of broadsheets dealing with exfoliative cytology, to be prepared jointly by the Association and the British Society for Clinical Cytology.

\section{Book reviews}

PRIMARY HYPERPARATHYROIDISM: A CRITICAL REVIEW By

L. N. Pyrah, A. Hodgkinson, and C. K. Anderson.

(Pp. 72; 43 figures. 17s. 6d.) Bristol: John Wright. 1966. This is specially reprinted from The British Journal of Surgery, April 1966. The subject is reviewed in detail and readably in 65 pages, illustrated with numerous reproductions of radiographs, photomicrographs, and a few coloured pictures. There are over 450 references. The aspects covered include pathology, and clinical picture, biochemical diagnosis, differential diagnosis, and treatment. The authors draw on their own experience of 68 cases of hyperparathyroidism and on hundreds more in the literature. It is made clear that the biochemist and morbid anatomist form an essential team with the surgeon in the diagnosis and treatment of the condition. This book is not only a guide to the pathologist as well as to the surgeon, physician, and radiologist: it presents a stimulating account of how the alert clinician is nowadays able to recognize early and minor stages of hyperparathyroidism and by successful surgery prevent the crippling effects of severe and advanced disease. The account of biochemical diagnosis and differential diagnosis is extra detailed and pays much attention to the numerous pitfalls. The contents include discussions of newer topics such as multiple endocrine adenomatosis, parathormonelike activity of occasional cancers of other organs. The book is highly recommended. It is informative, covers a lot in a short space, and will lead its readers to help to uncover yet more examples of hyperparathyroidism. The authors have not speculated on the aetiology of primary parathyroid adenomas or primary diffuse parathyroid hyperplasia and one cannot blame them. I. DONIACH

TREATMENT OF HAEMOPHILIA AND OTHER COAGULATION DISORDERS Edited by Rosemary Biggs and R. G. Macfarlane. (Pp. xiv + 391; illustrated. 75s.) Oxford: Blackwell Scientific Publications. 1966.

Professor Macfarlane and Dr. Biggs and their colleagues have unrivalled experience of all aspects of the treatment of haemophilia, and by their development of the preparation and use of highly concentrated antihaemophilic globulin from animal sources they have enabled major surgery to be undertaken in such patients with conspicuous success. In this book the various members of the Oxford team-physician, surgeon, and laboratory workers-each describe their experience of the treatment of haemophilia and related disorders in great detail from their own point of view; in doing so, they underline the importance of team work and close attention to detail in the management of bleeding episodes, and of surgical procedures in particular. In the final chapter, on haemophilia as a social problem, Macfarlane and Biggs put forward their views on the role of the haemophilia treatment centre, and make a plea for the establishment of one or two major centres in Britain, supported by a number of centres for diagnosis and the treatment of minor episodes. This conclusion is powerfully supported by the remainder of the book, which illustrates the advantages of such an approach in terms not only of 